\title{
DETERMINATION OF CROSS-SECTIONAL AREAS OF STRUCTURAL MEMBERS
}

\author{
By James A. Miller
}

\section{ABSTRACT}

The cross-sectional areas of structural members are often required for computing the stresses corresponding to the applied loads. The areas of many lightweight members cannot be obtained accurately from either nominal or measured dimensions. For example, in thin-walled members small differences in thickness cause large percentage errors in area. Often the shape of a section does not permit adequate measurements of the dimensions required to calculate the area. In such cases it is often advantageous to obtain the average cross-sectional area by a volumetric method if the cross section is uniform. If the cross section varies in area from section to section the area of a given section can sometimes be obtained from the average area of a short specimen taken from that location.

The method is illustrated by a determination of cross-sectional area for a typical airship box girder, fabricated from sheet aluminum alloy. The cross-sectional area varied because of a row of flanged circular lightening holes along each side and was a minimum at sections through the centers of the holes. Specimens 0.3 inch long were taken symmetrical to a minimum section. The end surfaces were ground smooth and nominally parallel so that the lengths could be measured accurately. The volume was determined by hydrostatic weighing. A correction was applied to the average cross-sectional area of these specimens to obtain the minimum cross-sectional area. The estimated uncertainty of the determination was \pm 0.4 percent.

\section{CONTENTS}

I. Introduction

II. Methods of determining cross-sectional areas

1. Nominal dimensions . .

2. Measured dimensions

3. Planimeter

4. Volumetric methods . . .

(a) Members of constant cross section.

(b) Members of varying cross section.............. 625

III. Procedure for applying a volumetric method to members of variable cross section _............ 626

1. Selection of specimens

2. Disassembling portion of girder containing specimens...... 627

3. Preparation of specimens_... .

(a) Cutting out blanks.... 628

(b) Finishing blanks........ 628

4. Determination of length

5. Determination of volume

6. Computation of cross-sectional area.

IV. Discussion .

1. Time required

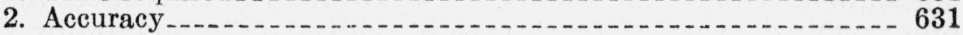


V. Summary

VI. Appendix A. Derivation of approximate formulas for computing the minimum cross-sectional areas of specimens having flanged circular holes . . . 632

VII. Appendix B. Calculation of volume from apparent loss in weight .... 636

\section{INTRODUCTION}

A knowledge of the cross-sectional area is frequently required in structural tests, in order to determine stresses in the structure from the external loads applied to it. In a compressive test, for example, the stress is equal to the load divided by the cross-sectional area of the specimen. It is evident, though not always appreciated, that the accuracy of the computed stress depends just as much on the accuracy of the cross-sectional area as upon the accuracy of the load.

For large structural members, cross-sectional areas computed from the nominal dimensions are usually considered adequate. For small members which have relatively compact sections of simple geometric shape the actual dimensions can be measured easily and the area can be computed readily.

Members have been built in recent years, however, which have cross sections of such size and shape that their areas cannot be obtained with sufficient accuracy from either the nominal or the measured dimensions. Members of this kind were involved when, at the request of the Bureau of Aeronautics of the Navy Department, the National Bureau of Standards undertook an investigation of the strength of aluminum-alloy airship girders of the two types shown in figure 1 and figure 2. The volumetric method for determining cross-sectional areas, described in this paper, was developed with the financial support of the Bureau of Aeronautics, Navy Department. A publication of the method seemed desirable because of its applicability to many other structural members, the areas of which cannot be obtained accurately from the usual mensuration formulas. It has been used in this Bureau to determine the cross-sectional areas of airplane wing beams, streamline tie rods, tubing, and other rolled, drawn, or extruded members.

\section{METHODS OF DETERMINING CROSS-SECTIONAL AREAS}

\section{NOMINAL DIMENSIONS}

When cross-sectional areas are computed from the nominal dimensions, the maximum difference between the cross sections of two members having the same nominal dimensions may be obtained from the specified tolerances. These tolerances frequently amount to \pm 5 percent of the thickness in the case of thin sheet. Structural members of a given design formed of such sheet, as for instance the airship girder shown in figure 2, may, therefore, differ by as much as 10 percent in cross-sectional area on account of the thickness tolerances alone. Spreads in thickness as great as 6 percent of the nominal value have been found in relatively small groups of girders having the same nominal dimensions. To the effect of tolerances in thickness one must add that of tolerances in width. The maximum difference in cross-sectional area due to the width tolerances would amount to 5.2 percent in these particular girders. 


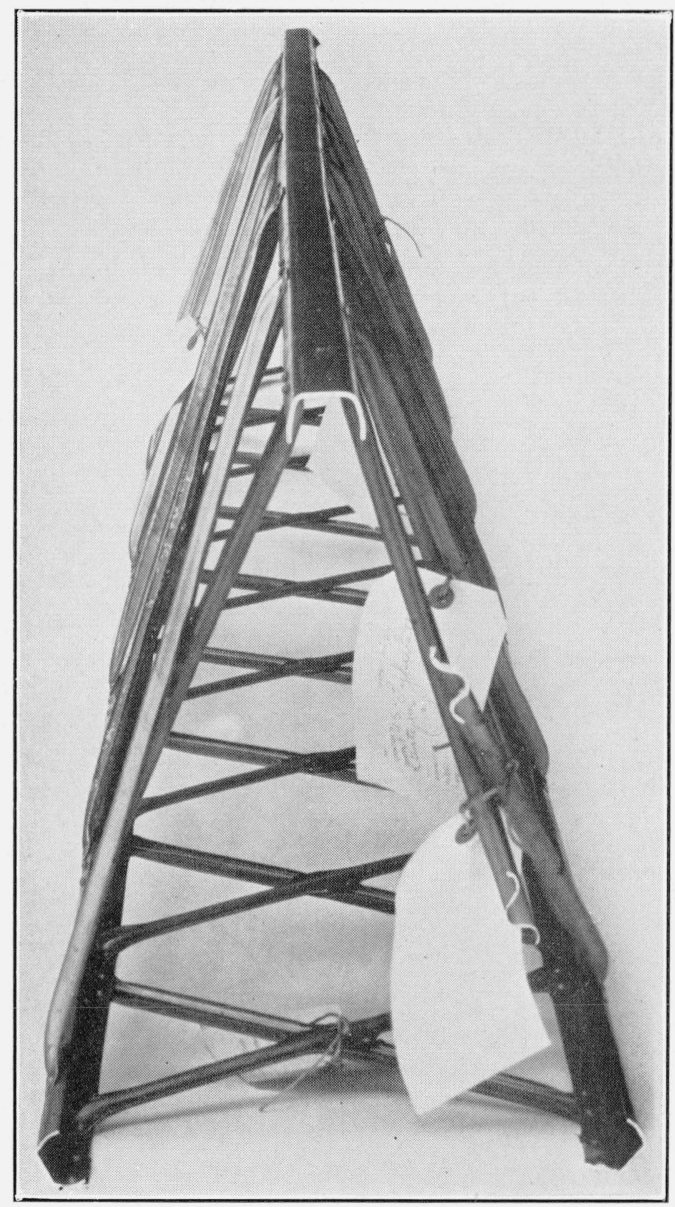

FiguRE 1.-Airship lattice girder.

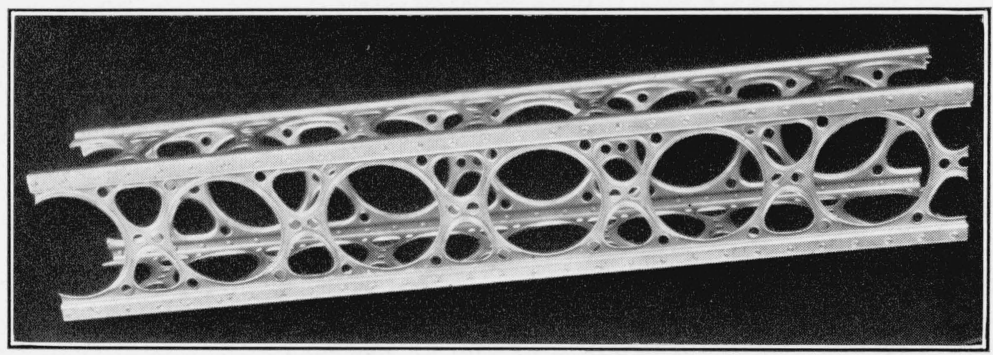

Figure 2.-Airship box girder. 
In cases where the variation from the nominal area is largely due to variation of one of the dimensions, a fairly accurate estimate of the cross-sectional area may be obtained by using an accurate measured value of this dimension and the nominal value of the other dimension.

\section{MEASURED DIMENSIONS}

Cross-sectional areas may be obtained directly from the measured dimensions for cross sections which are compact and of geometrically simple shape. The cross-sectional areas of members fabricated from formed sheet can sometimes be approximated by the product of the developed width of the sheet and an average value of the sheet thickness.

The following indirect method is used in this laboratory to estimate the developed widths of such sections. A strip of thin paper approximately $1 / 4 \mathrm{in}$. wide is fitted snugly about one lateral surface of the material so that the longitudinal axis of the strip lies in the plane of the section being measured. If the surface is reentrant, a good fit may be obtained using a strip coated with a pressure-sensitive adhesive, such as transparent Scotch tape. The strip is creased at the edges between which the width is desired. Then the strip is laid out flat and the distance between the creases is measured. The width of the opposite surface may be measured in the same way. These two measurements are averaged to obtain the developed width of the section.

If the strip can be fitted around one lateral surface of the section only, the developed width may be taken as the distance between creases for this surface minus a correction $\alpha t / 2$, where $\alpha$ is the rotation of the normal to the surface in passing from one end of the section to the other (see appendix A, fig. 7 a) and $t$ is the thickness of the sheet. For example, in measuring a closed surface on the outside, this correction amounts to $\pi t$. When the defining marks are on the outside of the strip, $t$ should be taken as the wall thickness of the section plus the thickness of the measuring strip. However, for a thin strip the resulting error is negligible in all practical cases.

The accuracy of such a measurement of the developed width depends on the form of the edges and the practicability of fitting a strip of paper to the surface without appreciable error due to lack of contact and extension of the strip.

The accuracy of the measured values of wall thickness is an even less definite quantity. It is only rarely possible to obtain a properly weighted average thickness, taking into account variations in thickness due to forming operations. Also, observational errors, both constant and variable, in the measurements are likely to be somewhat greater for formed sheet than for smooth flat materials.

It may be concluded that the method cannot be relied upon to give accurate results for members fabricated from formed sheet metal.

\section{PLANIMETER}

Areas of cross sections of irregular shape may be measured by tracing a contour of the cross section with the tracing point of a planimeter. This contour may be either an impression or an enlarged photograph of the cross section. 
It appears from the work of Stang, Sweetman, and Gough, ${ }^{1}$ who applied the method to concrete-reinforcement bars, that the dimensions of the contour as computed from the area may be in error by as much as $0.01 \mathrm{in}$. For a thin section there may be appreciable errors due to burrs or bevel at the edges. The planimeter method is therefore not suitable for an accurate determination of the cross-sectional area of thin-walled sections.

\section{VOLUMETRIC METHODS}

\section{(a) MEMBERS OF CONSTANT CROSS SECTION}

If the cross section of a member is constant, its area can be computed by dividing the volume of the member by its length. For a long member a suitable length may be cut from the member to serve as an "area specimen."

The end surfaces of an area specimen should be plane and perpendicular to the axis of the specimen. This may require special methods of finishing the end surfaces for specimens shorter than 1 in.

The volume of an area specimen may be obtained by one of the following methods:

1. The immersion method.-The specimen is immersed in a liquid (preferably one having low surface tension, such as alcohol) contained in a cylindrical glass graduate. The volume of the specimen is the increase in the graduate reading due to the immersion.

2. The weight method.-The specimen is weighed and the mass is divided by the density.

3. The hydrostatic-weighing method.-The difference between the weight of the specimen and its apparent weight in a liquid of known density is determined. This difference is equal to the weight of the liquid displaced by the specimen. The mass of the liquid displaced divided by its density is therefore equal to the volume of the specimen.

The choice of the volumetric method to be used depends to some extent upon the size and shape of the specimen, the equipment available, the accuracy desired, and also the number of specimens of the same material for which the cross-sectional areas are required.

The precision of the immersion method depends to the greatest extent upon the size and shape of the specimen. If the specimen is slender and requires a relatively small volume of liquid to fill the graduate to its capacity, results can sometimes be obtained by this method which compare favorably with those obtained by the other volumetric methods.

The precision of the weight method does not depend upon the shape of the specimen or of the cross section. This is true also for the hydrostatic-weighing method, provided all adhering air bubbles are removed. Neither does the precision of these methods depend upon the cross-sectional area, provided that the specimen can be taken long enough to keep the percentage error in volume within the required limits. These methods, therefore, are especially suited to members of constant section whose area cannot be conveniently computed or measured-for example: thin-walled members, such as tubing and the chord members of airship lattice girders, and streamline rods and other rolled, drawn, or extruded members.

2 BS J. Research 9, 512-514 (1932) RP486. 
The weight method is the most convenient method to use when the density of the material is known. Usually a specimen can be weighed with such precision that the error in volume due to the error in weight is negligible. Average values for the densities of structural materials are given in the literature; but the actual values for some alloys may differ appreciably from the average value because of differences in the composition, especially if the constituents have widely different densities. For example, for a group of 16 specimens of formed sheet aluminum alloy of a given nominal composition the difference between the highest and lowest values of density was 1.7 percent of the mean value, and for the chord members of a single girder this difference was 0.7 percent.

The hydrostatic-weighing method is generally used to obtain the volume of a solid specimen whose density is to be determined. With the apparatus and procedure to be described later, the volume of a specimen exceeding $1 \mathrm{~cm}^{3}$ can be measured to 0.17 percent. When the density of the material is not accurately known, it is advisable to use this method either to obtain the volume of the specimen or to determine the density of the material so that the weight method can be used. The latter procedure is usually to be preferred if the volume of the specimen is too small for accurate hydrostatic weighing or if more than one volumetric determination on specimens of the same material is required.

\section{(b) MEMBERS OF VARYING CROSS SECTION}

The applicability of the weight method and of the hydrostaticweighing method to thin-walled members of constant cross section suggests the possibility of using them to determine the minimum cross-sectional areas of thin-walled members of varying cross sectionfor example, airship box girders, similar to that shown in figure 2, in which the cross-sectional area of each strip of metal composing the

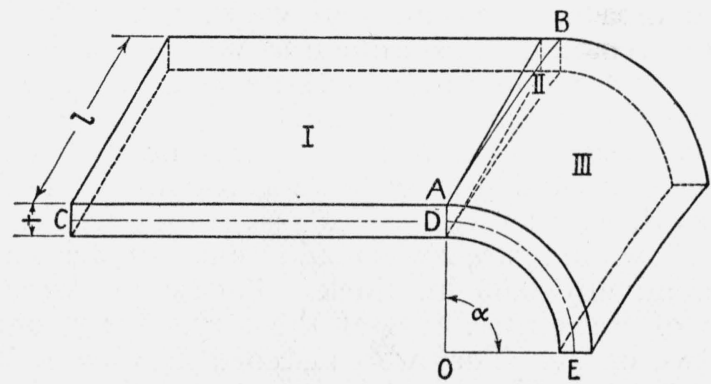

FigURE 3.-Hypothetical specimen for computation of excess volume.

"The following values were assumed: $r$, radius of $A B=1.625$ in.; $t=r / 32 ; O D=O E=r / 8 ; \alpha=90^{\circ} ; l=0.3$ in.; $w=C D+C E=0.9$ in. The minimum cross-sectional area, $A_{0}=w t$. The "minimum volume" $=A_{0} l$.

sides varies because of flanged holes. Some of the flanges curve sharply from the plane of the sheet and are for the most part perpendicular to it. Other flanges are curved throughout, as indicated in figure 3. The minimum cross section between a round hole and an edge of a strip is that cut by a plane through the center of the hole and perpendicular to the longitudinal axis of the strip. 
The volume of an area specimen cut from such a girder is somewhat larger than the "minimum volume" (the product of the area of the minimum cross section and the length).

The procedure for calculating the excess volume will be illustrated by a hypothetical case which imposes geometrical restrictions as severe as, and in some cases more severe than, any thus far encountered in area specimens from airship girders. This is shown diagrammatically in figure 3. The specimen may be considered as composed of three portions: I, which has constant cross section throughout; III, the flange generated by a quarter annulus, to which part of the excess volume is due; and the intermediate portion II, which is entirely an excess volume. One of the ends coincided with the minimum section, area $=A_{0}$, that is, it was in the plane through the center of the hole and perpendicular to the edges of the sheet. The specimen would therefore have the same relative excess as a symmetrical specimen of twice the length.

Volume III was calculated exactly by integration between the end surfaces of the specimen. A more convenient approximate solution for volume III was obtained by applying Pappus' theorem, that is, by multiplying the area of the generating quarter annulus by the length of the arc traversed by its centroid. A convenient approximate solution for the total excess volume was obtained from eq 4 and 5 derived in appendix A. All three methods gave values for total excess volume which checked within 0.01 percent of the "minimum volume." Approximate and convenient considerations such as those given in appendix A seem, therefore, adequate for computing excess volumes of area specimens of this general type.

\section{PROCEDURE FOR APPLYING A VOLUMETRIC METHOD TO MEMBERS OF VARIABLE CROSS SECTION}

The use of volumetric methods for determining the minimum cross-sectional area of a specimen of varying cross section requires refinements in preparing the specimen as well as consideration of the variation of cross section throughout its length. The problem involved will be illustrated by an airship box girder with circular lightening holes (fig. 2). It is hoped that the procedure followed, together with its discussion, may serve as a guide in determining the procedure for other structures.

The girder shown in figure 2 was made from four strips of aluminumalloy sheet nominally $0.05 \mathrm{in}$. thick. The strips were flanged to form corners of the girder, two of the strips being outside at the corners and two inside. They were fastened together at the corners of the girder by rivets. Holes had been cut and flanged in each strip according to a pattern which was repeated at regular intervals throughout its length. The cross-sectional area was a minimum at sections perpendicular to the longitudinal axis of the girder through the centers of the large circular holes. For the outside strips the dimensions $w, d$, and $f$ required to determine the excess volume (see appen$\operatorname{dix} \mathrm{A})$ were $2.05,3.70$, and 0.09 in., respectively. For the inside strips these dimensions were $1.20,4.55$, and 0.15 in., respectively.

Let us consider the various steps in determining the minimum cross-sectional area of this girder. 


\section{SELECTION OF SPECIMENS}

It is important that the specimen be of convenient size, large enough for accurate measurements of length and volume but not too large to obtain the minimum area accurately from the average area. A practical lower limit of length for area specimens prepared by the procedure outlined below is about 0.2 in. The upper limit of length depends upon the type of variation of section with length. It is frequently determined by the presence of irregularities, such as rivet holes, at or near the minimum section. In such cases it may be necessary to choose between a symmetrical specimen which includes the hole and an unsymmetrical specimen which avoids the hole. In general, these should be taken respectively longer and shorter than the corresponding symmetrical specimens without such irregularities. If it is necessary to include a rivet hole in a specimen, the minimum length may depend upon the size of the hole and the accuracy with which its volume may be obtained. For such a specimen it is advisable to include at least about 0.05 in. of the material on each side of the hole. It is recommended that the hole be made cylindrical with a sharp drill of known diameter before the specimen blank is cut out. The rivet hole is usually located in a relatively flat portion of the specimen, so that a few measurements of the thickness of the material in that region will give the average thickness of the material which is lacking. From these measurements the volume of the hole is computed and added to the volume of the area specimen to obtain the volume of the full specimen before dividing by the length to obtain the cross-sectional area.

For the airship girder that is used as an illustrative example, it was possible to obtain symmetrical specimens 0.3 in. long. The specimens from the outside and inside sheets had nominal volumes of $0.5 \mathrm{~cm}^{3}$ and $0.3 \mathrm{~cm}^{3}$, respectively. The location of the minimum cross section and identification symbols for each specimen were marked on the girder by lightly scratching with a sharp scriber.

\section{DISASSEMBLING PORTION OF GIRDER CONTAINING SPECIMENS}

A portion of the girder containing the specimens and extending 2 or 3 in. beyond them on each side was cut from the girder. The rivets in this portion were then removed and the parts were separated, care being taken not to mar or deform the specimens. There were then four formed strips of metal from which the area specimens were to be cut.

\section{PREPARATION OF SPECIMENS}

The end faces of area specimens should be perpendicular to the longitudinal axis of the member. For short specimens the end faces should, in addition, be plane and parallel in order to make possible accurate length measurements.

Each specimen was prepared by first cutting out a blank, the cuts being made normal to the longitudinal axis of the strip, and then grinding the ends until the greatest difference in length did not exceed one-half of 1 percent. 


\section{(a) CUTTING OUT BLANKS}

The blanks were cut from the formed strips by two metal slitting saws mounted on the arbor of a plain milling machine. The distance between the saws was the desired length of the blank, 0.3 in., plus about 0.01 in. for finishing the ends by grinding. The strips were held in the fixture shown in figure 4 . The plate, $A$, having a bar, $B$, at one end, was attached to the table of the milling machine with the bar parallel to the arbor of the machine. Clearance slots had been milled through the bar and in the plate. The blanks were cut out as follows.

The formed strip was placed in the fixture as shown in figure 4, with the minimum cross section centered between the clearance slots. The strip was clamped with one corner against the bar and the plate. The blank was then cut from the strip, the portions supported by the fixture being cut last. The other corner of the strip was then clamped in a similar position and the opposite blank was cut out.

\section{(b) FINISHING BLANKS}

The blanks were mounted in Wood's metal in a steel ring and were finished on a surface grinder equipped with a magnetic chuck.

One end of each blank was first tested for planeness on a flat plate. If the blank rocked or tilted, the end of the blank was rubbed on a wide smooth-cut mill file.

Two blanks were then arranged symmetrically about a tapped hole in the flat plate, $C$, figure 5, and clamped with the piece of sheet metal, $D$, having $1 / 16$-in. sheet rubber cemented to the lower surface. The contacts of the blanks with the plate were checked under a slight pressure before the screw was tightened.

A steel ring cut from pipe and having one end finished on a surface grinder was placed around the blanks with the finished end in contact with the plate. It was clamped by the strap, $E$.

The entire assembly was immersed in boiling water. It was removed when the temperature of the plate was higher than the melting point of the Wood's metal. Each ring was filled with Wood's metal that had been melted in a bath of boiling water. It was found desirable to have about $1 / 8$-in. clearance around the blanks so that the Wood's metal would flow freely around them.

The plate, $C$, was almost completely immersed in cold water so that the Wood's metal would solidify first at the bottom. This procedure minimized the effects of volume changes during the cooling and solidification of the molten metal.

The castings were then removed from the plate. Any projections of Wood's metal which might be touched by the grinding wheel were leveled with a heated piece of metal.

Several castings were held on the surface grinder by a magnetic chuck which had been checked to make sure that the working surface was true. A grinding wheel recommended by the manufacturer for grinding aluminum alloys was used with kerosene as the lubricant. The upper ends of the blanks were ground smooth, using feeds of about 0.001 in. and a much lighter feed for the finishing cut.

The castings were removed from the grinder and immersed in boiling water to melt the Wood's metal and release the blanks. The burrs on the ground edges were removed with a piece of aluminum 


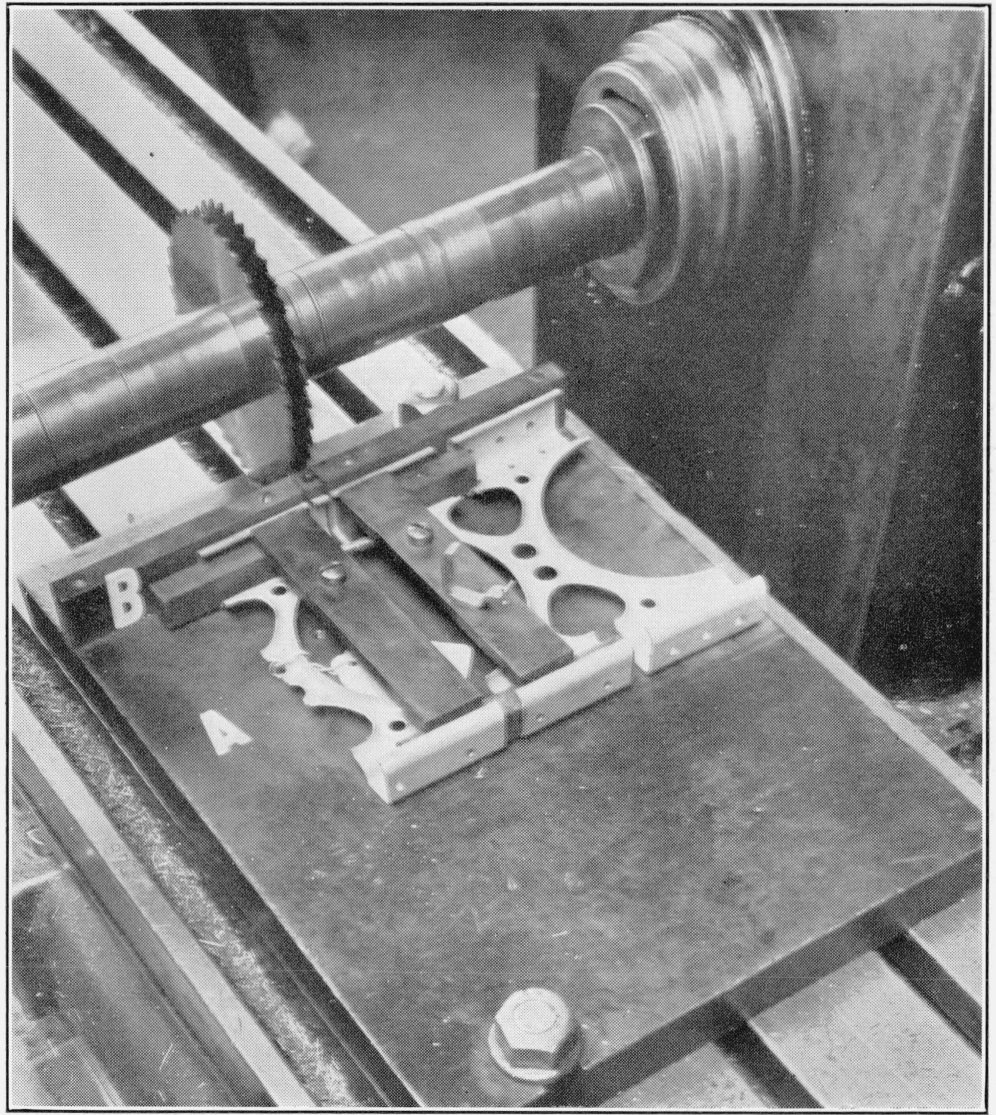

Figure 4.-Cutting out blanks.

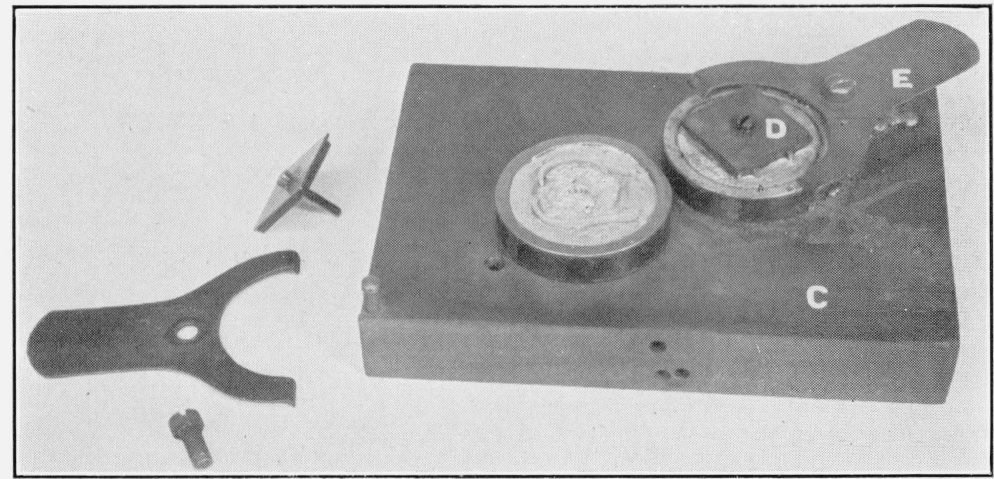

Figure 5.-Blanks mounted in rings. 


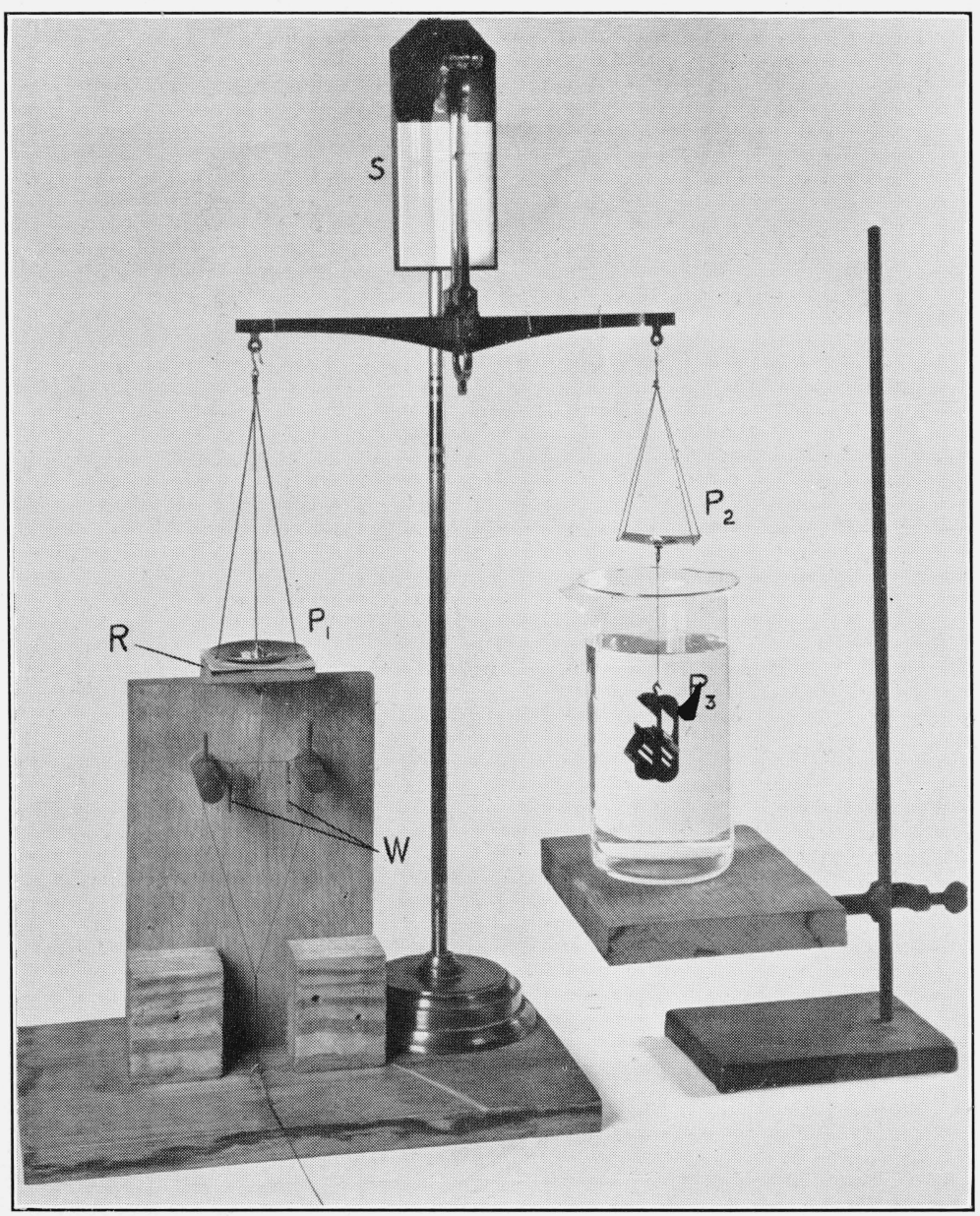

FiguRE 6.-Mohr balance used to determine volumes of area specimens. 
alloy, care being taken not to bevel the edges, and the ground surface was lapped superficially on a roughly ground cast-iron plate. This procedure was repeated until all of the burr was removed.

The preparation of each area specimen was completed by repeating the finishing procedure for the other end of the blank.

During the whole finishing procedure it is important that the surfaces be clean when they are brought into contact, so that the blanks and castings do not become tilted.

\section{DETERMINATION OF LENGTH}

For measuring the length of a specimen, micrometer calipers were used. The readings were estimated to one-tenth of a division (0.0001 in.).

The length of each specimen was measured at from 10 to 15 equally spaced locations. A specimen the length of which varied more than one-half of 1 percent was reground on one end.

\section{DETERMINATION OF VOLUME}

The specimens were grouped together for a volumetric determination and the hydrostatic-weighing method was used. This appeared to be the most convenient procedure, since the density of the material was not accurately known and since the specimens were of the same length and the cross-sectional areas at the individual corners were not required.

In applying the hydrostatic-weighing method, the volume specimen consisting of a group of area specimens was placed on one pan of a balance and was counterbalanced. Then, while suspended from the same pan, it was immersed in a liquid of known density, and the system was balanced by adding weights to that pan.

The volume was determined with the Mohr balance shown in figure 6. Pan $P_{1}$ of the balance could be held against a pan rest, $R$, by two weights, $W$, on a cord passing through a wire loop fastened to the bottom of the pan. The cord was so arranged that when it was pulled taut, the weights were raised, allowing the beam to swing. The amplitude of the swing could be controlled by raising the weights slowly.

A pan, $P_{2}$, for holding the specimens when weighing them in air was provided for the right arm of the beam. A holder, $P_{3}$, for supporting the specimens while they were being weighed in water was suspended from the bottom of the pan $P_{2}$ by a 0.003 -in. copper wire.

In order to determine the position of the pointer which passed through a slot in the support of the central bearing of the balance and consequently was least easily observed when the beam was nearly balanced, a light was so placed that the shadow of the slot and pointer could be observed on a screen, $S$, back of the balance.

The liquid used was distilled water. Good results were obtained by using a very fine wire for suspending the specimen holder by having the wire in the same position relative to the surface of the water for each balancing operation and by observing the following procedure.

The apparatus was assembled as shown in figure 6 . The wire for suspending the specimen holder was cleaned with alcohol and examined for kinks and other irregularities. The water level was adjusted 
so that that portion of the wire which passed through the surface of the water was smooth. Any air bubbles adhering to the specimen holder were removed.

The left-hand pan was held against the rest whenever specimens or weights were being changed.

The specimen was given a final cleaning with alcohol and allowed to dry, after which it was always handled with tweezers.

The temperature of the water was observed and recorded to $0.5^{\circ} \mathrm{C}$.

The specimen was placed on the right-hand pan and was approximately counterbalanced by weights on the other pan. The beam was finally balanced with a 5-mg rider on the right arm of the beam. The amplitude of the swing of the beam was made very small before the final balancing by slowly raising the weights for holding the pan against the rest as the pointer neared the zero position and by manipulating the 5 -mg rider. The final balancing procedure was as follows:

The 5-mg rider was placed on the right arm of the beam near the knife-edge and was then moved to the right along the beam until the right side was definitely heavy. It was then moved toward the left until the right side was definitely light. After the first trial the rider was carefully moved about one-fifth of a division at a time to keep the amplitude of swing of the beam small. The procedure was repeated until successive averages of maximum and minimum readings checked within about three-tenths of a division $(0.00015 \mathrm{~g})$. The average of these two values was recorded to 0.1 division.

The specimen was removed from the pan with tweezers, immersed in the distilled water, and then placed on the specimen holder after any adhering air bubbles were removed. If difficulty was experienced in removing air bubbles from the specimen, it was dipped in alcohol, then in distilled water, and then placed on the specimen holder. Weights were placed in the right pan to balance the buoyant force of the water on the specimen. An approximate balance was obtained with a $10-\mathrm{mg}$ rider set at a division mark, and the final balancing was done as before with the 5 -mg rider. The average reading for the 5 -mg rider was recorded, also the weight represented by the $10-\mathrm{mg}$ rider (0.001 g per division) and the weights in the right pan.

It was generally possible to obtain successive values for the apparent loss in weight that checked within 0.1 percent for a specimen measuring not less than $1 \mathrm{~cm}^{3}$.

The volume was calculated from the apparent loss in weight, using factors given in the third column of table 2 in appendix B.

If the density of the specimen is desired and an analytical balance is not available, the weight in air may be obtained by balancing the system without the specimen by adding additional weights to the right pan.

\section{COMPUTATION OF CROSS-SECTIONAL AREA}

The average cross-sectional area of the specimen was calculated by dividing the volume by the average length. A correction computed from eq 5, appendix A, was applied to obtain the minimum crosssectional area. 


\section{DISCUSSION}

\section{TIME REQUIRED}

The time required for determining the cross-sectional area of a girder such as the one described was found to be approximately 20 man-hours for the selection and preparation of the eight specimens treated as a group and $3 \frac{1}{2}$ man-hours for the determination of volume and length. The time is necessarily increased when the cross-sectional areas at the various corners are desired or when it is necessary to take specimens of different lengths.

\section{ACCURACY}

Since the cross-sectional area is given by the ratio of volume to length, the accuracy of its value depends upon the combined errors in the length and volumetric measurements.

The error in length will depend on the shape of the specimen and on the deviation of the end surfaces from parallelism and from perpendicularity to the longitudinal axis of the specimen. For a specimen 0.3 in. long from the airship box girder, figure 2 , it was estimated from a detailed study that the average of the length measurements was between 0.16 percent less and 0.20 percent greater than the actual average length. This figure was derived as the sum of an error of from -0.03 to +0.10 percent due to errors in the micrometer caliper measurements resulting from deviation of the end surfaces from parallelism, an error of from -0.06 to 0 percent due to deviation from perpendicularity of the end surfaces, an error of from 0 to +0.03 percent due to surface irregularities, and an error of \pm 0.07 percent in setting and reading the micrometer calipers.

A detailed study was also made of the possible errors in the volume determination. It was concluded that the volume obtained for a specimen or a group of specimens 0.3 in. long, having a total volume greater than $1 \mathrm{~cm}^{3}\left(0.061 \mathrm{in.}^{3}\right)$, was within \pm 0.17 percent of the actual volume. This figure was derived as the sum of an error of \pm 0.02 percent due to the tolerances for the class $\mathrm{S}^{2}$ weights used in the determination and an error of \pm 0.15 percent obtained from a statistical study of a large number of volume determinations by two observers.

The total possible error in the minimum cross-sectional area for a symmetrical specimen, without holes, of the type considered was estimated by adding the errors in length and the errors in volume and adding to these a possible error of \pm 0.01 percent in the value of excess volume (see appendix $\mathrm{A}$, table 1 ). This results in a total possible error of from -0.38 to +0.34 percent.

The total possible error in minimum cross-sectional area of a symmetrical specimen of the same type but with a 0.2 -in. rivet hole was estimated to be from -0.70 to +0.66 percent due to an additional estimated error of \pm 0.32 percent in determining the volume lacking because of the hole (see appendix $\mathrm{A}$, table 1 ).

The total possible error for an unsymmetrical specimen of the same type which would avoid a 0.2 -in. rivet hole having its center in the minimum section was estimated to be from -0.71 to +0.59 percent.

\footnotetext{
${ }^{2}$ See Cir. BS C3 [3d ed], 26 (1918).
} 
The error is greater than for the symmetrical specimen of the same length because of an increase in the possible error of the excess volume (see appendix A, table 1).

\section{SUMMARY}

1. If a structural member has a cross section of simple geometric shape and of sufficient size for accurate measurement, the crosssectional area can be determined readily and satisfactorily from the measured dimensions.

2. For other structural members the average cross-sectional area over a given length can be determined more accurately by volumetric methods.

3 . The hydrostatic-weighing method and the weight method were found to be the most satisfactory of the volumetric methods.

4. For a structural member the cross sections of which differ in size, the minimum cross-sectional area can be determined by volumetric methods if the relationship between the minimum and the average cross-sectional areas of a suitable area specimen is known.

5. Frequently the specimen can be taken sufficiently short so that the difference between the average and minimum cross-sectional areas may be estimated or even neglected without materially affecting the accuracy of the result.

6. If short area specimens are used the end surfaces should be plane and parallel so that the length can be measured accurately.

7. The minimum cross-sectional area of a symmetrical area specimen, free from holes, $0.3 \mathrm{in}$. long, and having a volume of $1 \mathrm{~cm}^{3}$, can be determined, by the volumetric method described, with an error of less than 0.4 percent. If there are holes near the minimum cross section, this percentage may be approximately 0.7 percent.

The author expresses his indebtedness to his associates in the engineering mechanics section for their helpful cooperation, in particular to C. S. Aitchison for valuable advice and assistance in many ways. He is also grateful to G. C. Klein, formerly of the instrument shop, and A. Altman, of the machine shop, for assistance in developing the procedure for preparing the specimens, and to members of the Weights and Measures Division for valuable suggestions and for making check volumetric determinations.

\section{APPENDIX A}

\section{Derivation of Approximate Formulas for Computing the Minimum} Cross-Sectional Areas of Specimens Having Flanged Circular Holes

Consider a formed strip of sheet metal such as was used in the girder, figure 2. The minimum cross section is that cut by a plane through the center of one of the large circular holes and perpendicular to the longitudinal axis of the strip.

Consider, for convenience, the material between a hole and one edge of the strip, indicated by its minimum cross section in figure 7 (a). An area specimen is taken from this region, with its end surfaces parallel to the minimum section. 


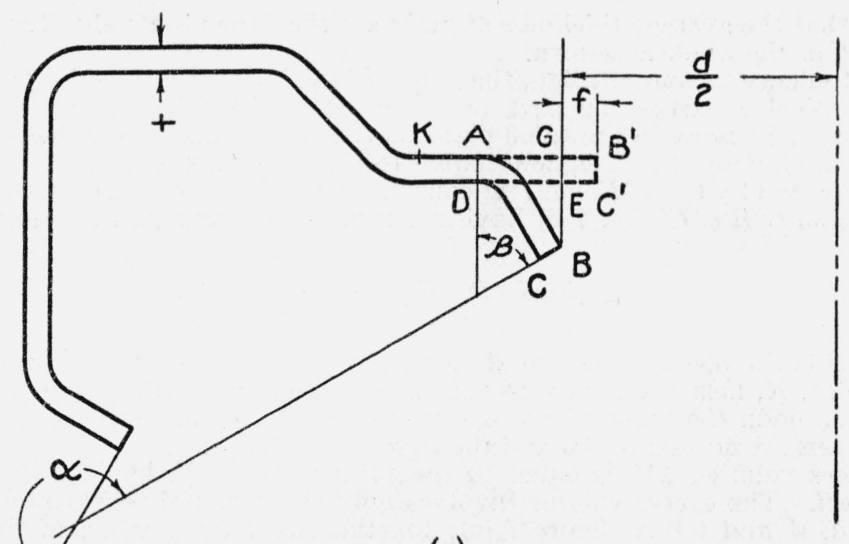

(a)

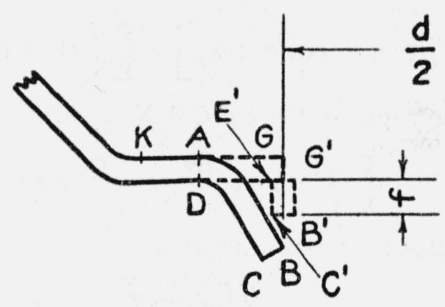

(b)

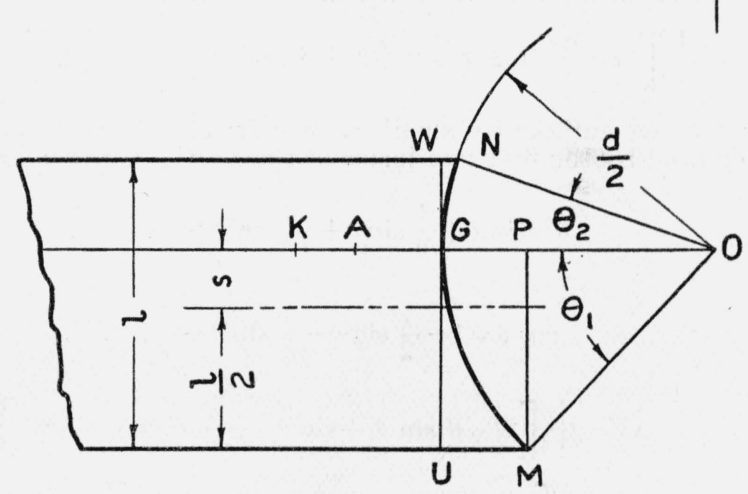

(c)

Figure 7.-Assumed distribution of fange material for deriving eq 5.

Let $l=$ length of area specimen

$d=$ inside diameter of hole

$s=$ distance from minimum section to midlength of specimen

$\theta_{1}=\sin ^{-1} \frac{l+2 s}{d}$

$\theta_{2}=\sin ^{-1} \frac{l-2 s}{d}$

$w=$ developed width of specimen. (See page 623, also fig. 7 a.) 
Assume that the average thickness at and near the flange is equal to the average thickness, $t$, of the whole specimen.

For convenience in computation, the flange of the hole is replaced by two mutually perpendicular parts - one part (represented by its minimum cross section $A G E D$ in fig. 7 a) lying in the same plane as that of the material adjacent to the flange and having an inside diameter equal to the hole diameter, $d$, and the other part (represented by $G B^{\prime} C^{\prime} E$, fig. 7 a) considered to be part of a tube (represented by the section $G^{\prime} B^{\prime} C^{\prime} E^{\prime}$, fig. $7 \mathrm{~b}$ ) having a mean diameter equal to $d$ and length equal to

$$
f=K A B-K A G-\frac{\beta t}{2},
$$

where $K A B$ is the distance measured along the outside of the flange from a convenient point, $K$, near the flange, to the edge of the flange; $A G$ is the projection of the flange upon the plane of the material adjacent to the flange; and $\beta$ is the angle between the normal to $A G$ and the edge of the flange.

The excess volume, $\Delta V$, is equal to the total volume, $V$, less the "minimum volume," wtl. The excess volume involves only the material represented by the portions $U G M$ and $G W N$, figure 7 (c), together with the portion of the flange replaced by a tube.

The volume represented by $U G M$ is equal to

$$
t\left[\frac{d^{2}}{4}\left(\sin \theta_{1}\right)-\frac{d^{2}}{8}\left(\sin \theta_{1} \cos \theta_{1}+\theta_{1}\right)\right]=t\left[\frac{d}{4}(l+2 s)-\frac{d^{2}}{8}\left(\sin \theta_{1} \cos \theta_{1}+\theta_{1}\right)\right] .
$$

Similarly the volume represented by $G W N$ equals

$$
t\left[\frac{d}{4}(l-2 s)-\frac{d^{2}}{8}\left(\sin \theta_{2} \cos \theta_{2}+\theta_{2}\right)\right] .
$$

The excess for the tubular portion equals

$$
\frac{t f d}{2}\left(\theta_{1}+\theta_{2}\right)-t f l \text {. }
$$

Adding these three expressions results in a total excess volume

$$
\Delta V=t\left\{\frac{d}{4}\left[2 l-\frac{d}{2}\left(\sin \theta_{1} \cos \theta_{1}+\theta_{1}+\sin \theta_{2} \cos \theta_{2}+\theta_{2}\right)\right]+\frac{f d}{2}\left(\theta_{1}+\theta_{2}\right)-f l\right\} .
$$

If $\theta_{1}$ and $\theta_{2}$ are sufficiently small, as will frequently be the case, $\theta$ and $\cos \theta$ may be replaced by the first two terms of their series expansions:

and

$$
\theta=\sin \theta+\frac{1}{6} \sin ^{3} \theta+\frac{3}{40} \sin ^{5} \theta+\ldots .
$$

so that

$$
\cos \theta=1-\frac{1}{2} \sin ^{2} \theta-\frac{1}{8} \sin ^{4} \theta-\ldots .
$$

$$
\begin{aligned}
\Delta V & =t\left\{\frac{d}{4}\left[2 l-d\left(\sin \theta_{1}+\sin \theta_{2}\right)+\frac{d}{6}\left(\sin ^{3} \theta_{1}+\sin ^{3} \theta_{2}\right)\right]\right. \\
& \left.+\frac{f d}{2}\left[\sin \theta_{1}+\sin \theta_{2}+\frac{1}{6}\left(\sin ^{3} \theta_{1}+\sin ^{3} \theta_{2}\right)\right]-f l\right\} .
\end{aligned}
$$

Substituting in eq 3 the values for $\sin \theta_{1}$ and $\sin \theta_{2}$ given respectively in eq 1 and 2 , we obtain

$$
\Delta V=\frac{l t}{d}\left(1+\frac{2 f}{d}\right)\left(\frac{l^{2}}{12}+s^{2}\right)
$$

The ratio, $E$, of excess volume, $\Delta V$, to "minimum volume" $w t$ ?, which is also the ratio of the excess cross-sectional area to minimum cross-sectional area, is

$$
E=\frac{\Delta V}{w t l}=\frac{1}{w d}\left(1+\frac{2 f}{d}\right)\left(\frac{l^{2}}{12}+s^{2}\right)
$$


To obtain $\Delta E$, the error in $E$ due to an error $\Delta s$ in $s$, substitute $s+\Delta s$ for $s$ in eq 5 and subtract eq 5 from the resulting expression. This gives

$$
\Delta E=\frac{\Delta s}{w d}\left(1+\frac{2 f}{d}\right)(2 s+\Delta s) .
$$

Calculations of $E$ and of $\Delta E$ and other possible errors in the minimum crosssectional area of the girder considered in the illustrative example are given in table 1. Calculations are also given for unsymmetrical specimens and for additional errors due to rivet holes at the minimum section.

TABLE 1.-Calculation of excess, E, and possible errors in minimum cross-sectional area for area specimens from a box girder with circular lightening holes

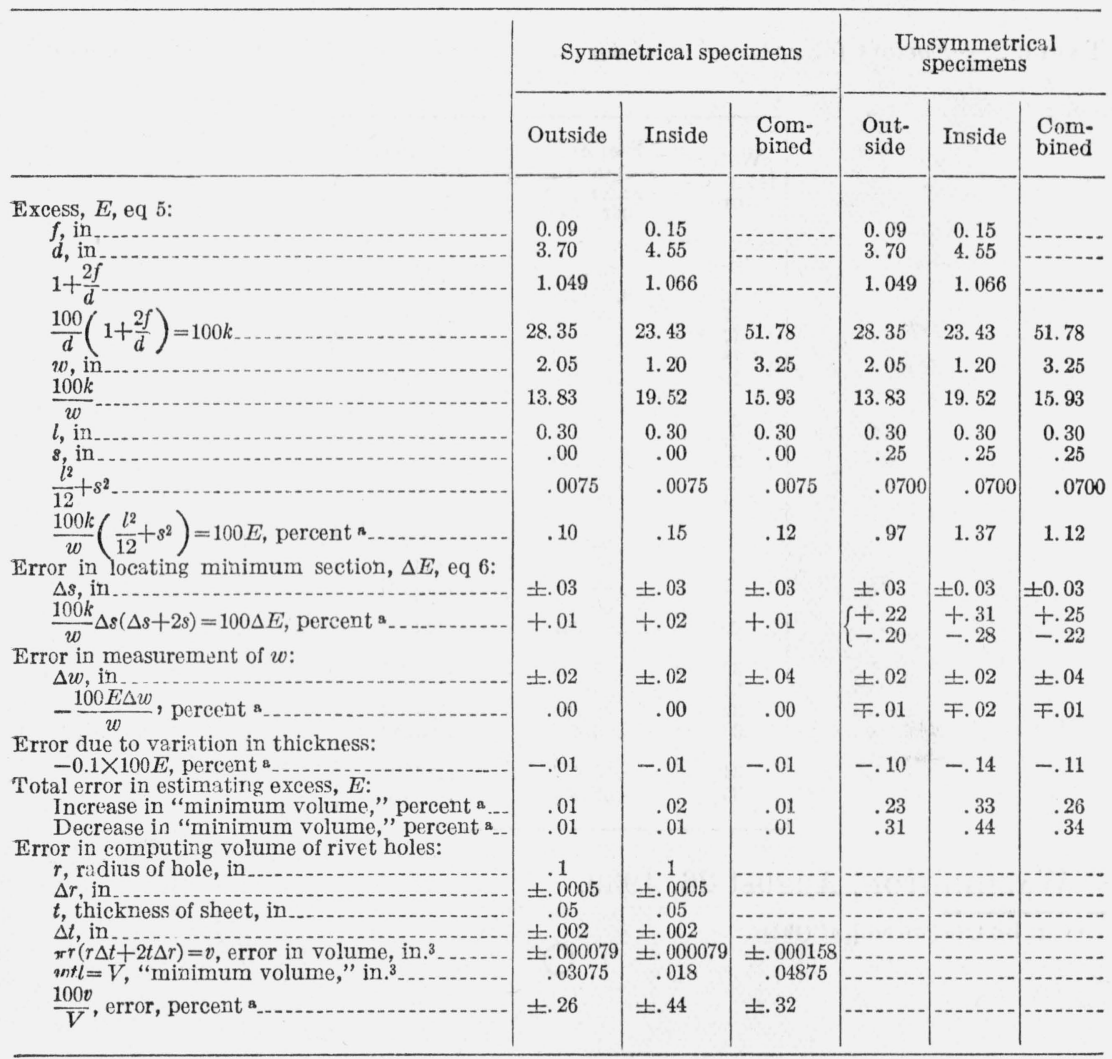

a Percentage of "minimum volume." 


\section{APPENDIX B}

\section{Calculation of Volume From Apparent Loss in Weight}

The volume of a specimen, measured in cubic inches, can be calculated from its apparent loss in weight, measured in grams, when immersed in water, by making use of table 2. The factors in this table were calculated from standard density tables for distilled water at $15^{\circ}$ to $35^{\circ} \mathrm{C},{ }^{3}$ assuming the density of the weights to be $8.4 \mathrm{~g} / \mathrm{cm}^{3}$ and the density of the air to be $0.0012 \mathrm{~g} / \mathrm{cm}^{3}$. The second column of table 2 gives the volume of the specimen at the water temperature; and the third column gives the volume for duralumin specimens at $25^{\circ} \mathrm{C}$, obtained from the volume at water temperature, assuming a coefficient of linear expansion of $23 \times 10^{-6} /{ }^{\circ} \mathrm{C}$.

TABLE 2.-Factors for conversion of apparent loss in weight in water $(g)$ into volume (in..$\left.^{3}\right)$

\begin{tabular}{|c|c|c|}
\hline $\begin{array}{l}\text { Water } \\
\text { tempera- } \\
\text { ture }\end{array}$ & $\begin{array}{l}\text { Factors for } \\
\text { specimens at } \\
\text { water tem- } \\
\text { perature }\end{array}$ & $\begin{array}{l}\text { Factors for } \\
\text { duralumin } \\
\text { specimens } \\
\text { at } 25^{\circ} \mathrm{C}\end{array}$ \\
\hline $\begin{array}{l}{ }^{\circ} \mathrm{C} \\
15 \\
16 \\
17 \\
18 \\
19\end{array}$ & $\begin{array}{c}\text { in. } .^{3 / g} \\
0.061143 \\
.061153 \\
.061163 \\
.061174 \\
.061186\end{array}$ & $\begin{array}{c}i n .3 / g \\
0.061185 \\
.061191 \\
.061197 \\
.061203 \\
.061211\end{array}$ \\
\hline $\begin{array}{l}20 \\
21 \\
22 \\
23 \\
24\end{array}$ & $\begin{array}{l}.061198 \\
.061211 \\
.061224 \\
.061239 \\
.061253\end{array}$ & $\begin{array}{l}.061219 \\
.061228 \\
.061237 \\
.061247 \\
.061258\end{array}$ \\
\hline $\begin{array}{l}25 \\
26 \\
27 \\
28 \\
29\end{array}$ & $\begin{array}{l}.061269 \\
.061285 \\
.061302 \\
.061319 \\
.061337\end{array}$ & $\begin{array}{l}.061269 \\
.061281 \\
.061293 \\
.061306 \\
.061320\end{array}$ \\
\hline $\begin{array}{l}30 \\
31 \\
32 \\
33\end{array}$ & $\begin{array}{l}.061355 \\
.061374 \\
.061394 \\
.061414\end{array}$ & $\begin{array}{l}.061334 \\
.061349 \\
.061364 \\
.061380\end{array}$ \\
\hline $\begin{array}{l}34 \\
35\end{array}$ & .061434 & $\begin{array}{l}.061396 \\
.061413\end{array}$ \\
\hline
\end{tabular}

Washington, August 26, 1939.

'Cir. BS C19 [6th ed.], 47 (1924). 